\title{
Traits of relevance to improve yield under terminal drought stress in chickpea (C. arietinum L.)
}

\author{
J. Kashiwagi a,*, L. Krishnamurthy ${ }^{\text {b }}$, P.M. Gaur ${ }^{\text {b }}$, H.D. Upadhyaya ${ }^{\text {b }}$, R.K. Varshney ${ }^{\text {b }}$, S. Tobita ${ }^{c}$ \\ a Crop Science Lab, Graduate School of Agriculture, Hokkaido University, Kita 9, Nishi 9, Kita-ku, Sapporo 060-8589, Japan \\ b International Crops Research Institute for the Semi-Arid Tropics (ICRISAT), Patancheru 502-324, Andhra Pradesh, India \\ c Japan International Research Center for Agricultural Sciences (JIRCAS), Ohwashi 1-1, Tsukuba 305-8686, Japan
}

\section{A R T I C L E I N F O}

\section{Article history:}

Received 14 February 2013

Accepted 14 February 2013

\section{Keywords:}

Chickpea

Crop growth rate

Drought response index

Rate of partitioning

Terminal drought

Water use efficiency

\begin{abstract}
A B S T R A C T
In chickpea (Cicer arietinum L.), terminal drought is a major constraint that limits seed yield. It is important to establish the relative importance many of these drought-related traits for prioritizing their consideration in breeding for drought tolerance improvements. By associating various traits with the drought response index (DRI), a good indicator devoid of the confounding effects of drought escape and yield potential, well associated traits to grain yield under drought were investigated. Twenty-one genotypes with known diversity in drought response were used. Genotype ICC 7571 was identified newly as a consistent and highly drought tolerant chickpea germplasm. The DRI showed significant positive association with crop growth rate (CGR) and negative association with water use efficiency (WUE) in both the years. The DRI also showed a positive association with the pod quantity per unit area irrespective of the drought intensity. The harvest index and the rate of partitioning $(p)$ showed a close positive association with DRI under severe drought stress. The relationship of $p$, as an associated trait with yield, intensified further under severe drought. This adaptive expression suggests that $p$ to be considered as a critical trait while breeding for drought tolerance.
\end{abstract}

(C) 2013 Elsevier B.V. All rights reserved.

\section{Introduction}

Chickpea (Cicer arietinum L.) is the third most important food legume which has a total global production of $11.6 \mathrm{M}$ tons from 13.2 $\mathrm{M}$ ha in 2011 (FAOSTAT, 2012). Most chickpea producing areas are in the arid and semi-arid zones, and approximately $90 \%$ of world's chickpea is grown under rainfed conditions (Kumar and Abbo, 2001) where terminal drought is one of the major constraints for the productivity. Terminal drought stress is typical of the postrainy season in the semi-arid tropical regions, and determined by the rainfall and the evaporative demand before and during the crop season, and also the soil characteristics. Terminal drought stress is the consequence of the crop growing and maturing in a progressively depleting soil moisture profile (Ludlow and Muchow, 1990; Krishnamurthy et al., 1999). Chickpea is usually cultivated in such environments.

Under terminal drought, drought escape by early crop duration and the yield potential were shown to contribute to drought yield (Bidinger et al., 1987a, b). In short-duration terminal drought environments, the existence of a strong negative correlation of yield

\footnotetext{
* Corresponding author. Tel.: +81 11 7063878; fax: +81 117063878 .

E-mail address: jkashi@res.agr.hokudai.ac.jp (J. Kashiwagi).
}

with duration directed crop improvement efforts to concentrate more in developing short duration cultivars as a short term strategy to escape terminal drought (Kumar et al., 1985; Kumar and Rao, 2001). This strategy of breeding for drought escape had successfully brought the yield stability in chickpea (Gowda et al., 2009). However, these early maturing chickpea cultivars had to pay a yield penalty due to the cut in their total photosynthetic period. The long term chickpea breeding strategy for terminal drought continues to be the exploitation of the whole available duration, and thereby increase the drought yields as well as their stability by transgressing large number of traits that are known to confer yield advantages particularly under drought.

In the last decade, substantial progress was made toward improving the drought yield through the strength of the root system as more soil water was expected to be absorbed by larger root system and the subsoil water could be tapped by deeper root system. Under terminal drought, total root biomass of chickpea at an early stage of growth was shown to contribute to yield at maturity in a previous work, particularly by maximizing transpiration over evaporation of water stored into the surface layers $(15-30 \mathrm{~cm})$ of the soil profile (Kashiwagi et al., 2006a). This study also showed that the relevance of enhanced soil water extraction through deeper rooting became apparent only when drought intensity became severer. Also, the recently documented existence of a large 
diversity for root biomass, root prolificacy and rooting depth in chickpea mini core germplasm accessions (Kashiwagi et al., 2005), encourages efforts of improvement through enhanced absorption.

The soil water use under water-limited environments can be visualized to occur in two major categories, namely, (1) active soil water use and (2) conservative water use. With the active soil water use strategy, high transpiration could be sustained by rapid and more soil mining through profuse and deep root systems and this would be expected to produce more yield under drought through large biomass production. A possible risk can be premature drying up of soil water leaving the reproductive growth to suffer. In chickpea, better maintenance of stomatal conductance under drought environments measured through the plant canopy temperature indicated a significant contribution of continued active transpiration during peak pod development toward grain yield (Kashiwagi et al., 2008b). This indicated the existence of active self-regulation of plant size sensing the current status of quantum soil water. Rare occurrences of premature drying of chickpea crop in the fields, rather than a poor crop growth and yield, support this presumption. In conservative soil water use, in contrast, the advantage would be less risk of soil water deficit during the reproductive stage, but it might result in less yield under drought. The current shoot biomass production under drought is close to $2.8 \mathrm{tha}^{-1}$ (Kashiwagi et al., 2006a) that is too low compared to the cereals shoot biomass production. Recently, the advantage of conservative water use during the vegetative growth stage was demonstrated in chickpea in a cylinder culture, and a low canopy conductance was proposed as an important trait (Zaman-Allah1 et al., 2011).

Agricultural productivity cannot be improved through traits that support survival. Most of the drought survival traits, therefore, have not been applied in plant breeding except assimilate reserve remobilization (sink activity) (Blum, 2005). The advantage of high rate of sink activity for seed yield under drought environments was clearly highlighted in chickpea (Krishnamurthy et al., 1999). This would be used as indicative traits in active water use strategy. Thus, more highly mobile stored assimilates in the plant organs could remediate the potential disadvantage from more biomass.

Several studies have been conducted, and valuable information has been generated for a targeted chickpea breeding program to improve the productivity under drought environments. Such studies largely focused on a single or a few target traits, especially root traits, in the last decade. Very little effort had been made toward identification of other potentially important traits apart from the root traits for drought yield improvements in chickpea. Therefore, the major objective of this study was to evaluate the relative importance of various other drought-related traits that might contribute to yield stability under terminal drought for further breeding efforts in chickpea.

\section{Materials and methods}

\subsection{Crop management}

Field trials were conducted during the post-rainy seasons in 2004-2005 and 2005-2006 on a Vertisol (fine monotmorillonitic isophyperthermic typic pallustert) at ICRISAT, Patancheru $\left(17^{\circ} 30^{\prime}\right.$ $\mathrm{N} ; 78^{\circ} 16 \mathrm{E}^{\prime}$; altitude $549 \mathrm{~m}$ ) in India. Twenty one diverse chickpea genotypes for their response in field performances to drought stress, Annigeri, ICC 10755, ICC 1230, ICC 12654, ICC 13219, ICC 14098, ICC 14199, ICC 14595, ICC 1510, ICC 15294, ICC 15518, ICC 1882, ICC 283, ICC 4958, ICC 5337, ICC 6537, ICC 7308, ICC 7571, ICC 8261, ICC 9137 and ICC 9402 were used in this study. The soil depth of the fields was $\geq 120 \mathrm{~cm}$, and the soils could hold about $230 \mathrm{~mm}$ of plant available water in the $120 \mathrm{~cm}$ (maximum rooting depth) soil profile. The fields were solarized by spreading polythene mulch during the summer season to minimize the soil-borne diseases, particularly to eradicate Fusarium oxysporum wilt causing fungi. Glyphosate (Roundup ${ }^{\circledR}$ ) herbicide was applied before the land preparation only during 2005-2006. The broad bed and furrows with $1.2 \mathrm{~m}$ wide beds flanked by $0.3 \mathrm{~m}$ furrows were prepared in fields for both trials. Surface application and incorporation of $18 \mathrm{~kg} \mathrm{Nha}^{-1}$ and $20 \mathrm{~kg} \mathrm{Pha}^{-1}$ as di-ammonium phosphate was made in both trials.

The plot size in both trials was $4 \mathrm{~m} \times 2$ rows, and a $3 \times 7$ alpha design was used with three replications. As main plot treatments, two irrigation schemes were set, that is, non-irrigated treatment to impose drought stress except for a post-sowing irrigation, and irrigated treatment for optimal plant growth by irrigation depending on the need (Total amount of irrigation given was $200 \mathrm{~mm}$ in four events in 2004-2005, and $180 \mathrm{~mm}$ in four events in 2005-2006). Seeds were treated with $0.5 \%$ Benlate ${ }^{\circledR}$ (E.I. DuPont India Ltd., Gurgaon, India) and Thiram ${ }^{\circledR}$ (Sudhama Chemicals Pvt. Ltd., Gujarat, India) mixture in both trials. The trials were hand-planted at the first opportunity after the cessation of rains on 28 October 2004, and 26 November 2005. The distance between rows was $30 \mathrm{~cm}$ with $10 \mathrm{~cm}$ between plants. The sowing depth was at $3-5 \mathrm{~cm}$ with two seeds per hill which was later thinned to one. In both trials, the fields were inoculated with Rhizobium strain IC59 by liquid inoculation method (Brockwell, 1982). A $50 \mathrm{~mm}$ irrigation through perforated pipes in 2004, and a $20 \mathrm{~mm}$ in 2005 was applied the next day of sowing to ensure proper emergence. Successive irrigations in the irrigated treatments were applied through furrow irrigation. Adequate plant protections from pod borer (Helicoverpa armigera) were given, and the plots were kept weed free by manual weeding during the cropping seasons in both trials.

Through regular phenology observation, the date when $50 \%$ or more of the plants in a plot flowered was recorded as $50 \%$ flowering time of the plot. The topmost freshly and fully expanded (4-5th from the top) compound leaf from the dominant primary branches or main stems of plants were collected from all plots for $\Delta^{13} \mathrm{C}$ estimations in both trials at both 40 and 66 days after sowing (DAS) and at the harvest in 2005-2006. At physiological maturity (116 DAS), above ground parts of the plant were harvested to evaluate the yield and yield components. They were dried in hot air oven at $45^{\circ} \mathrm{C}$, and then total shoot dry weights were recorded. Grain weights were recorded after threshing. Harvest index (\%) was calculated as seed yield divided by total shoot biomass at maturity.

\subsection{Soil moisture measurements}

Access tubes for neutron moisture meter were installed at 2 spots in 2004-2005 and 7 in 2005-2006 in each replication and treatment at random. The neutron moisture meter (Depth Moisture Gauge, Model 3332, Troxler Electronic Laboratories Inc., NC, USA) readings at soil depths of $15 \mathrm{~cm}$ increments up to a depth of $120 \mathrm{~cm}$ were made before and after each irrigation. These measurements matched at approximately 10 day intervals or close by. The Troxler soil moisture observations were corrected using a calibration curve developed for each depth separately using the data collected gravimetrically across the season. Moisture content of the surface soil $(0-15 \mathrm{~cm})$ was measured only gravimetrically.

\subsection{Carbon isotope discrimination for the estimation of water use efficiency}

RuBP carboxylase fixes more ${ }^{12} \mathrm{CO}_{2}$ than ${ }^{13} \mathrm{CO}_{2}$, when intracellular $\mathrm{CO}_{2}$ concentration is adequate, but this enzyme fixes ${ }^{12} \mathrm{CO}_{2}$ and ${ }^{13} \mathrm{CO}_{2}$ at a ratio close to the air if the $\mathrm{CO}_{2}$ concentration is decreased by stomatal closure (Farquhar et al., 1989). This selectiveness is well recognized as the carbon isotopic discrimination $\left(\Delta^{13} C\right)$. By this nature of RuBP carboxylase, it is empirically demonstrated that the 
water use efficiency and $\Delta^{13} \mathrm{C}$ are negatively correlated in $C_{3}$ plants including chickpea (Kashiwagi et al., 2006b).

The leaf samples oven air dried at $80^{\circ} \mathrm{C}$ for $48 \mathrm{~h}$ were crushed into fine powder by a pulverizer. The powered leaf samples of $0.2 \mathrm{mg}$ were sealed into small tin capsules and were set on an isotope ratio mass spectrometer (ThermoFinnigan Delta XPplus, Hamburg, Germany) connected with an element analyzer (Carlo Erba EA Flash 1112, Milan, Italy) for $\delta^{13} \mathrm{C}$ (the ratio of ${ }^{13} \mathrm{C} /{ }^{12} \mathrm{C}$ of plant tissue) estimations at JIRCAS, Tsukuba, Japan. The $\Delta^{13} \mathrm{C}$ was then calculated as (Farquhar et al., 1982):

$\Delta^{13} \mathrm{C}=\frac{\left(\delta^{13} C_{\text {source }}-\delta^{13} C_{\text {sample }}\right)}{\left(1+\delta^{13} C_{\text {sample }} / 1000\right)}$

where $\delta^{13} \mathrm{C}_{\text {source }}$ is the $\delta^{13} \mathrm{C}$ of the air (-8\%), and $\delta^{13} \mathrm{C}_{\text {sample }}$ is the measured value for each sample.

\subsection{Growth analysis}

The hot-air oven dried shoot weights were used for the estimation of crop growth rate (CGR) as:

$\mathrm{CGR}=$ total shoot dry weight at final

harvest/growth period(days)

and, the partition coefficient $(p)$ or rate of partitioning to estimate the assimilate remobilization rate (sink activity) was calculated by a formula presented by Krishnamurthy et al. (1999).

$p=\frac{\text { seed yield } / \text { reproductive period in }{ }^{\circ} \mathrm{C} \text { day }}{\text { CGR }}$

where the reproductive period $={ }^{\circ} \mathrm{C}$ day for final harvest $-{ }^{\circ} \mathrm{C}$ day to reach $50 \%$ flowering.

\subsection{Drought response index (DRI)}

Two important traits, yield potential and crop duration, were recognized to influence seed yield under drought environments (Saxena, 1987). This means that high yielding genotypes may also yield better under drought while longer duration genotypes are disadvantaged as these are forced to fill their seeds under relatively increased drought and heat stress (Saxena, 1987). The standard residuals derived after removal of the effects of drought escape (early flowering) and yield potential (optimally irrigated yield) would be a good indication for the magnitude of genotypic drought avoidance/tolerance, and also could be used to associate with relevant traits and identify contributory traits to drought avoidance/tolerance (Bidinger et al., 1987a,b; Saxena, 1987, 2003; Krishnamurthy et al., 2010). The residuals can be computed through the multiple regression approach (Bidinger et al., 1987a,b). In this approach, the grain yield of a genotype under drought stress condition (Ys) can be expressed as a function of yield potential (Yp), time to $50 \%$ flowering (F), and a drought response index (DRI) as follows:

$\mathrm{Ys}=a+b \mathrm{Yp}+d \mathrm{~F}+\mathrm{DRI}+E$,

where $E$ is random error with zero mean and variance $\sigma$. Since the DRI can be computed as the standard residuals through the difference between the actual and estimated yields under stress upon the standard error of the estimated yield $(\sigma)$. For this multiple regression, $50 \%$ flowering $(F)$ under stress for every individual plot and for the yield potential (Yp) arithmetic mean across the three replications were considered.
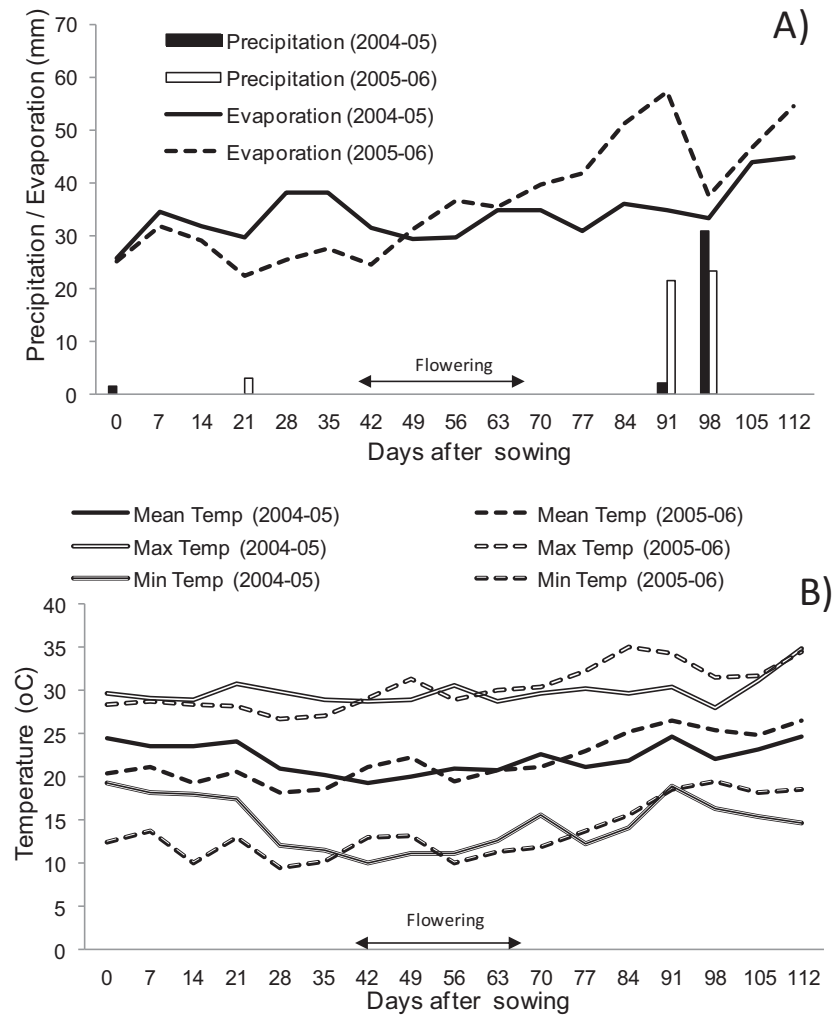

Fig. 1. Weather during the crop growing seasons in 2004-2005 and 2005-2006 Horizontal arrows mark the 50\% flowering phase of all the accessions in the trial. (A) Precipitation and evaporation, and (B) temperature.

\subsection{Statistical analysis}

The replication-wise DRI values were used for statistical analysis of each environment using ReML considering genotype as random. Variance components due to genotypes $\left(\delta_{g}^{2}\right)$ and error $\left(\delta_{e}^{2}\right)$ and their standard errors were determined. Environment wise best linear unbiased predictors (BLUPs) for the entries were calculated. Heritability was estimated as $h^{2}=\delta_{g}^{2} /\left(\delta_{g}^{2}+\delta_{e}^{2}\right)$. The significance of genetic variability among entries was assessed via the standard error of the estimate of genetic variance $\delta_{g}^{2}$, assuming the ratio $\delta_{g}^{2} / \mathrm{SE}\left(\delta_{g}^{2}\right)$ to follow normal distribution asymptotically. On the pooled analysis, homogeneity of variance was tested using Bartlett's test (Bartlett, 1937). Here, the year was treated as a fixed effect and the genotype $(G) \times$ environment $(E)$ interaction as random. The variance due to $(G)\left(\delta_{g}^{2}\right)$ and $(G) \times(E)$ interaction $\left(\delta_{g E}^{2}\right)$ and their standard error were determined. The significance of the fixed effect of the year was evaluated by the Wald statistic that asymptotically follows a $\chi^{2}$ distribution.

\section{Results}

\subsection{Growth environments during the trial periods}

The evaporation demand was greater than the precipitation during cropping seasons in both years (Fig. 1A), which means that the drought intensity was getting severer with the advancing age of the crop. This is a typical phenomenon of terminal drought environment. The climatic condition in the cropping period, however, was not similar between two seasons largely as a consequence of later sowing in 2005-2006. The air temperatures before flowering were higher in 2004-2005 than that in 2005-2006 (Fig. 1B). During the flowering period, however, there was a switching over and the post-flowering temperatures during 2005-2006 were higher than 


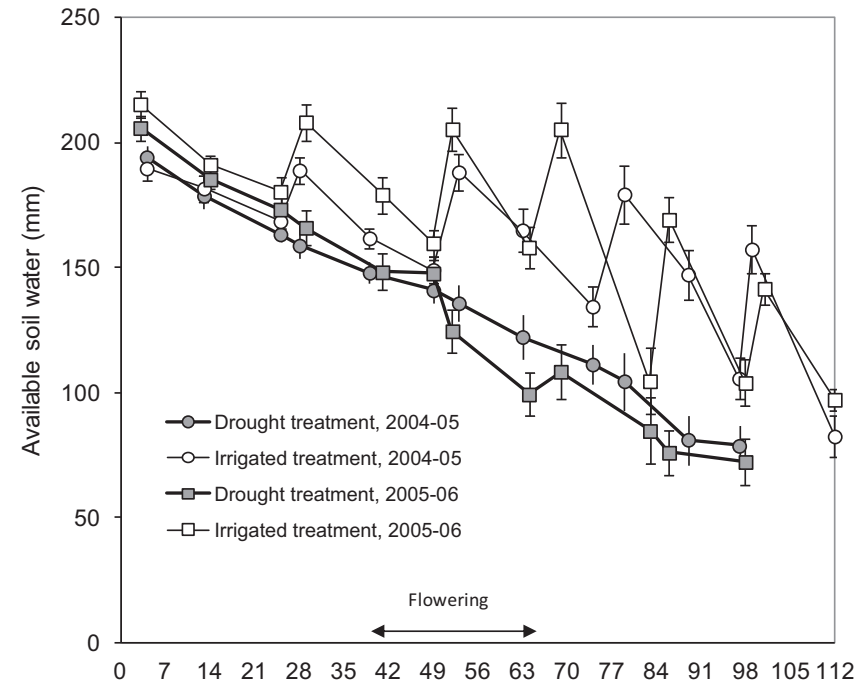

Days after sowing

Fig. 2. Changes in available soil moisture up to a soil depth of $1.2 \mathrm{~m}$ across the crop growing seasons of 2004-2005 and 2005-2006. Vertical bears denote standard error of differences $( \pm)$.

those in 2004-2005. The same trend was seen to exist on evaporation.

The soil water dynamics showed decreasing available soil moisture as the season advanced in both years (Fig. 2). Compared to 2004-2005, the available soil moisture in 2005-2006 was less after 49 DAS. Irrigations till the end of flowering stage in both years brought back the total available soil water to initial levels to fully support plant growth.

These indicate that the drought intensity during the vegetative growth period was severer in 2004-2005 than in 2005-2006, but during the reproductive stage, it was severer in 2005-2006 than in 2004-2005. Although there was one substantial rain at 91 DAS in 2005-2006, chickpea under drought could not benefit from this rainfall as this occurred at the approach of maturity or after maturity.

\subsection{Crop growth under terminal drought environments}

Genotypes varied in 50\% flowering in both 2004-2005 and 2005-2006 (Table 1). The mean 50\% flowering was early in 2004-2005 cropping season compared to 2005-2006. The range of flowering time under drought was slightly narrower in 2004-2005 than in 2005-2006. This overall phenology differences were likely due to the required thermal time accumulation for flowering.

Total shoot dry weight (TDW) under drought treatments showed substantial variation in both the years, and the mean TDW was larger in 2004-2005 (Table 1). Under drought stress, the mean harvest index (HI) and mean 100 seed weight were larger in 2004-2005 than in 2005-2006. These could reflect in better seed yield in 2004-2005 $\left(119.1 \mathrm{~g} \mathrm{~m}^{-2}\right)$ than in 2005-2006 $\left(85.9 \mathrm{~g} \mathrm{~m}^{-2}\right)$. In 2004-2005, the seed yield under drought environment showed a significant negative correlation with the flowering time, and a significant positive correlation with the yield potential under irrigation treatment (Fig. 3). It is known that the crop duration and potential yield were the two major traits that determine major part of the yield under terminal drought environments (Bidinger et al., 1987a,b; Krishnamurthy et al., 2010). In 2004-2005, the yield potential (yield under irrigation) could explain 56\% of the variation in drought yield, and the flowering time $85 \%$ of it. But these relations were loose in 2005-2006. This means that though the differences in time to flowering and yield potential explained large part of the drought yield variation, there are also other unknown characteristics that contributed to yields under drought.

The mean of crop growth rate (CGR) in 2004-2005 was slightly larger than that in 2005-2006 (Table 1). On the other hand, the mean partition coefficient $(p)$ in 2004-2005 was smaller compared to the $p$ in 2005-2006 (Table 1). This would be the influence of the drought pattern altered by late sowing in 2005-2006. The severer drought intensity after flowering in 2005-2006 might have forced the plants to remobilize the shoot dry matter to seeds rapidly compared to 2004-2005.

At all the sampling times $\Delta^{13} \mathrm{C}$, significantly varied among genotypes both in 2004-2005 and 2005-2006 (Table 1). The mean $\Delta{ }^{13} \mathrm{C}$ under drought environments were always smaller than those in the irrigated environments. The mean $\Delta^{13} \mathrm{C}$ in $2004-2005$ was less than those in 2005-2006 under drought both at 40DAS and 66DAS sampling as most vegetative growth was under cooler temperatures and high temperature stress-free in 2005-2006.

\subsection{Identifying the relevant contributory traits under terminal drought stress}

Although the drought and heat environments were not the same between years, viz., relatively severe during vegetative stage in 2004-2005 and severe during the reproductive stage in 2005-2006, the grain yield under drought between years was significantly correlated (Fig. 4A). This indicates that the genotypic responses are repeatable across years. However, the correlation coefficient was not so high as $0.482(p<0.05)$ which indicates that there were considerable genotype by environment $(G \times E)$ interactions existed for the drought yield, and some genotypes might have active mechanisms or traits to cope with the terminal drought.

As there were $G \times E$ interactions, the drought response indices (DRI) and drought yield was plotted separately for each year (Fig. 4B and $C$ ) and this association showed close correlation with the drought yields in both the years (Fig. 4B and C), which confirmed that chickpea genotypes with higher DRI are also better in drought yields (Krishnamurthy et al., 2010). There was a substantial range of variability for DRI among 21 chickpea genotypes in both the years (Fig. 4B and C). Some genotypes, ICC14098, ICC12654, ICC6537, ICC8261, Annigeri and ICC7571 were consistent in their positive DRI in both years. Especially, ICC7571 showed the best consistent DRI (Table 2).

Since the DRI is an index exclusive of crop duration and yield potential effects, it directly identifies genotypes that successfully avoid drought. However, it is further necessary to identify the traits that contribute to this superiority. The DRI was significantly-positively correlated with CGR $(0.645, p<0.01$ in 2004-2005; 0.653, $p<0.01$ in 2005-2006), and $\Delta^{13} C$ at 66 DAS $(0.457, p<0.05$ in 2004-2005; 0.641, $p<0.01$ in 2005-2006) in both the years (Table 3 ). This indicates that maintaining better crop growth rate would be important for improving the drought yield, and another noteworthy trait would be low water use efficiency till early reproductive stage as there is a significant negative correlation between $\Delta^{13} \mathrm{C}$ and WUE (Kashiwagi et al., 2006b).

The DRI showed a positive correlation with the pod quantity irrespective of the drought intensity (Table 3 ). The HI and $p$ showed a significantly positive correlation with DRI and the 100 seed weight correlated negatively with DRI in 2004-2005. This indicates that formation of an increased reproductive sink capacity would be an important trait to look for while improving drought yield, and the sink activity (assimilate remobilization rate) could be one major component in enhancing sink capacity that operates successfully when the drought becomes severer. 
Table 1

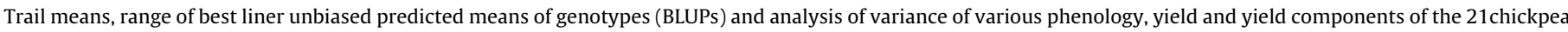
germplasm accessions in the field experiments during 2004-2005, and 2005-2006.

\begin{tabular}{|c|c|c|c|c|c|c|c|c|c|}
\hline \multirow[t]{2}{*}{ Trait } & \multirow[t]{2}{*}{ Year } & \multicolumn{2}{|c|}{ Trial mean } & \multicolumn{2}{|c|}{ Range of predicted means } & \multicolumn{2}{|l|}{ S.Ed } & \multicolumn{2}{|l|}{$\delta_{g}^{2}(\mathrm{SE})$} \\
\hline & & IR & DRY & IR & DRY & IR & DRY & IR & DRY \\
\hline \multirow{2}{*}{$50 \%$ flowering } & 2004-2005 & 47.4 & 44.5 & $37.9-60.7$ & $37.2-59.9$ & 1.5 & 1.6 & $48.8(15.8)$ & $44.9(14.6)$ \\
\hline & 2005-2006 & 52.7 & 49.0 & $39.4-66.2$ & $39.7-62.8$ & 1.7 & 2.3 & $46.4(15.2)$ & $45.8(15.4)$ \\
\hline \multirow[t]{2}{*}{ TDW } & 2004-2005 & 474.1 & 243.8 & $451.7-508.0$ & $231.9-259.8$ & 19.1 & 10.7 & $389.0(244.0)$ & $115.1(76.9)$ \\
\hline & 2005-2006 & 513.0 & 200.6 & $437.5-623.4$ & $159.6-273.4$ & 56.1 & 28.5 & $4087.0(2176.0)$ & $1232.0(595.0)$ \\
\hline \multirow[t]{2}{*}{ YLD } & 2004-2005 & 183.6 & 119.1 & $130.8-241.5$ & $53.5-158.0$ & 14.9 & 8.5 & $1296.3(448.4)$ & $737.2(245.2)$ \\
\hline & 2005-2006 & 191.5 & 85.9 & $188.3-194.5$ & $50.6-118.0$ & 8.1 & 15.1 & $37.0(143.0)$ & $416.9(184.3)$ \\
\hline \multirow[t]{2}{*}{$\mathrm{HI}$} & 2004-2005 & 38.9 & 48.8 & $26.2-52.0$ & $62.2-22.2$ & 2.8 & 2.4 & $63.3(21.4)$ & $118.7(38.4)$ \\
\hline & 2005-2006 & 38.4 & 43.6 & $26.48-51.14$ & $15.2-60.2$ & 2.5 & 3.0 & $58.0(19.4)$ & $122.8(40.3)$ \\
\hline \multirow{2}{*}{100 seed Wt } & 2004-2005 & 20.9 & 20.4 & $10.2-40.9$ & $11.3-34.4$ & 2.3 & 2.6 & $8.3(1.9)$ & $57.4(19.3)$ \\
\hline & 2005-2006 & 18.0 & 18.4 & $10.6-28.4$ & $9.6-30.2$ & 3.0 & 2.4 & $37.6(13.5)$ & $44.8(15.1)$ \\
\hline \multirow[t]{2}{*}{ CGR } & 2004-2005 & 4.49 & 2.57 & $4.32-4.88$ & $2.15-3.02$ & 0.18 & 0.15 & $0.04(0.02)$ & $0.06(0.02)$ \\
\hline & 2005-2006 & 4.75 & 2.14 & $4.34-5.24$ & $1.24-3.13$ & 0.41 & 0.30 & $0.15(0.12)$ & $0.23(0.08)$ \\
\hline \multirow[t]{2}{*}{$\Delta^{13} \mathrm{C} @ 40 \mathrm{DAS}$} & 2004-2005 & 19.70 & 18.89 & 19.13-20.03 & $18.05-19.47$ & 0.20 & 0.14 & $0.08(0.03)$ & $0.19(0.06)$ \\
\hline & 2005-2006 & 20.49 & 20.15 & 20.08-21.12 & $19.57-50.57$ & 0.23 & 0.22 & $0.11(0.05)$ & $0.07(0.03)$ \\
\hline \multirow[t]{2}{*}{$\Delta^{13}$ C@66DAS } & 2004-2005 & 19.21 & 17.93 & $18.4-19.81$ & $17.13-19.03$ & 0.20 & 0.19 & $0.19(0.07)$ & $0.25(0.08)$ \\
\hline & 2005-2006 & 20.39 & 19.39 & 19.71-21.04 & $18.55-50.54$ & 0.23 & 0.20 & $0.15(0.06)$ & $0.29(010)$ \\
\hline$\Delta^{13}$ C@harvest & 2005-2006 & 20.62 & 18.11 & $19.27-21.55$ & $16.31-19.66$ & 0.23 & 0.62 & $0.40(0.13)$ & $1.02(0.40)$ \\
\hline \multirow[t]{2}{*}{ Pod no. } & 2004-2005 & 1455.0 & 856.3 & $760-2339$ & $458.2-1812.2$ & 346.3 & 139.4 & $369,879.0(140,515.0)$ & $132,190.0(45,178.0)$ \\
\hline & 2005-2006 & 1512.0 & 624.7 & 719-2012 & $285.3-906.0$ & 279.1 & 158.1 & $158,619.0(67,476.0)$ & $43,722.0(19,754.0)$ \\
\hline \multirow[t]{2}{*}{ Partition coefficient } & 2004-2005 & 0.70 & 0.91 & $0.53-0.90$ & $0.47-1.16$ & 0.05 & 0.05 & $0.01(0.005)$ & $0.04(0.01)$ \\
\hline & 2005-2006 & 0.75 & 0.95 & $0.54-0.94$ & $0.40--1.36$ & 0.06 & 0.08 & $0.02(0.007)$ & $0.06(0.02)$ \\
\hline
\end{tabular}

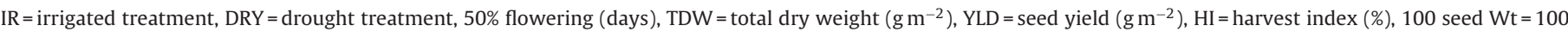
seed weight $(\mathrm{g}), \mathrm{CGR}=$ crop growth rate $\left(\mathrm{g} \mathrm{m}^{-2} \mathrm{day}^{-1}\right), \Delta^{13} \mathrm{C}(\%)$, Pod no. = number of pods $\mathrm{m}^{-2}$, partition coefficient $(\%)$.

\section{Discussion}

The key information that emerges out of this study is the shift in significance of traits across moisture environments or drought intensity. Under drought, the crop growth rate (CGR) was highly - positively associated with drought yield. But there was a shift between water use efficiency (WUE) and the rate of partitioning in their extent of association to the drought yield (Table 3). A
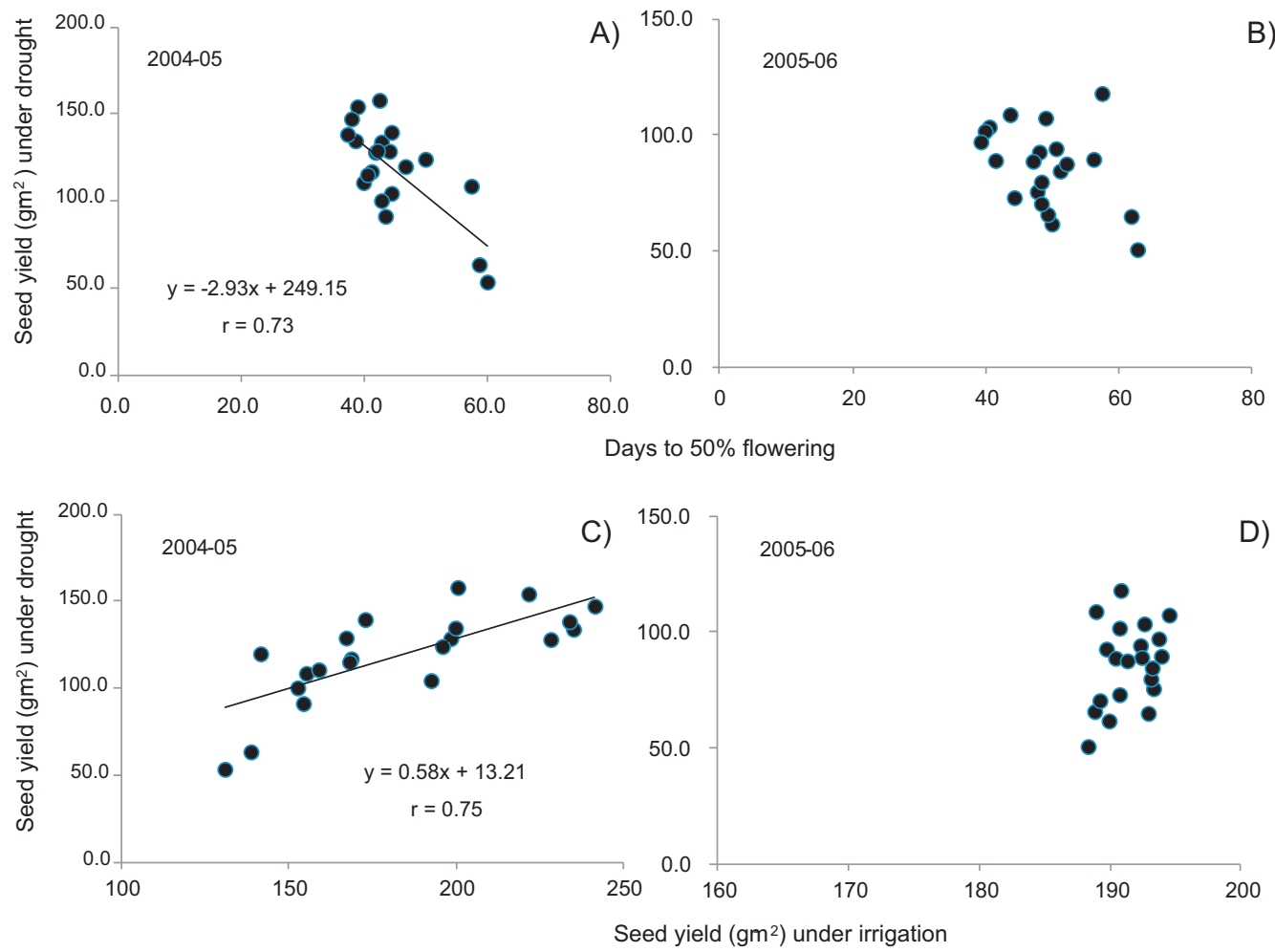

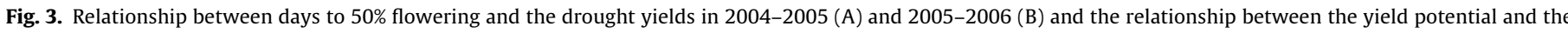
drought yields in 2004-2005 (C) and in 2005-2006 (D) 
Table 2

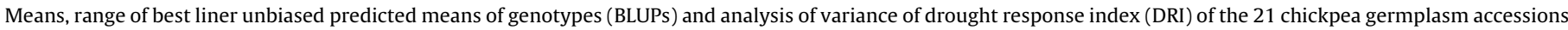
under drought treatments in 2004-2005 and 2005-2006.

\begin{tabular}{|c|c|c|c|c|}
\hline Year & Trial mean & Range of predicted means & S.Ed & $\delta_{g}^{2}(\mathrm{SE})$ \\
\hline 2004-2005 & 0.0 & $-1.07-1.38$ & 0.69 & $0.59(0.24)$ \\
\hline 2005-2006 & 0.0 & $-0.61-1.40$ & 0.50 & $0.36(0.18)$ \\
\hline
\end{tabular}

similar finding of the rate of partitioning explaining more variation in yield under drought was reported earlier (Krishnamurthy et al., 1999). This means that it is important to select the right combination of traits while breeding for drought tolerance and soil moisture


Fig. 4. Relationship between the drought yields of 2004-2005 and 2005-2006 (A), between drought response index (DRI) and drought yield in 2004-2005 (B), in 2005-2006 (C). environment targeted chickpea breeding efforts can lead to better success.

The CGR was positively correlated with DRI in both the years. Similar observation was made in soybean (Oya et al., 2004). The CGR could be considered as a trait for water harvesting since the total water use, viz. total transpiration, is strongly correlated with the plant growth (Udayakumar et al., 1998; Condon et al., 2002). This means that the increase in total transpiration result in greater CGR under water limited environments. It would be, therefore, desirable to maintain greater transpiration under drought environments so that greater biomass production can be maintained through greater CGR.

In our trials, the DRI showed a positive association with $\Delta^{13} \mathrm{C}$ during the flowering stage indicating a negative influence of WUE on DRI till that stage. The $\Delta^{13} \mathrm{C}$ could be considered as a trait for water utilization in situation where water is available, and higher $\Delta^{13} \mathrm{C}$ is mainly brought by higher total transpiration (Ashok et al., 1999; Blum, 2005). This result indicates that the active water use strategy to maintain greater transpiration till the flowering stage in chickpea would be relevant so that reasonably large enough early growth vigor could be achieved. In addition, since the pod quantity also showed a positive association with DRI, ensuring greater transpiration at the flowering stage is important to set larger number of pods. Once the pod set is successful, then, large amount of seed biomass can be obtained at the reproductive stage by rapid remobilization the current and stored assimilates from the stems and leaves (Krishnamurthy et al., 1999).

As in other crops, e.g. soybean (Sinclair et al., 2008), wheat (Merah, 2001) and rice (Kato et al., 2008), conservative water use was found to improve chickpea grain yield under drought grown in the tall cylinders (Zaman-Allah1 et al., 2011). The results showed that less soil water use during the vegetative growth stage could keep more soil water for their reproductive growth. Depending on the drought intensity, either active or conservative water use strategy would find relevance as well as the significance of the traits associated would possibly shift.

One of the major contributory traits to enable an active water use strategy would be a stronger root system for capturing more soil water during the growth period (Krishnamurthy et al., 2004; Kashiwagi et al., 2006a). Compared to most other legumes, root system of chickpea is known to be well adapted for growing under receding soil moisture conditions by possessing more number of thin xylem vessels facilitating effective, less energy-requiring soil moisture absorption (Purushothaman et al., 2013). Also in chickpea, a large genetic diversity has been reported on the root biomass as well as rooting depth, and promising genotypes were also identified (Kashiwagi et al., 2005). Though the heritability of the rooting depth was not high enough meriting consideration for breeding, the root biomass and root length density does merit (Kashiwagi et al., 2008a).

Although the efforts are underway to utilize these better rooting genotypes as breeding materials in drought yield improvement (Varshney et al., 2011), breeding for the root traits would be a challenging task. Based on this study, we could propose alternative traits such as $\Delta^{13} \mathrm{C}$ and partition coefficient $(p)$ as other useful indicators of drought tolerance. Compared to the root traits, $\Delta^{13} \mathrm{C}$ and $p$ permit high throughput and remain cost effective as selection tools. 
Table 3

Correlation coefficients between drought response index (DRI) and other drought avoidance/tolerance related traits under drought stress in $2004-2005$ and $2005-2006$.

\begin{tabular}{|c|c|c|c|c|c|c|c|c|}
\hline Year & $\Delta^{13} \mathrm{C} @ 40 D A S$ & $\Delta^{13} \mathrm{C} @ 66 \mathrm{DAS}$ & $\Delta^{13}$ C@harvest & $\mathrm{HI}$ & CGR & Pod no. & Pertition coefficient & 100 seed $\mathrm{Wt}$ \\
\hline 2004-2005 & 0.402 & 0.457 & - & 0.505 & 0.646 & 0.469 & 0.641 & -0.471 \\
\hline $2005-2006$ & 0.418 & 0.641 & 0.452 & 0.323 & 0.653 & 0.434 & 0.333 & -0.051 \\
\hline
\end{tabular}

$\mathrm{HI}=$ harvest index, $\mathrm{CGR}=$ crop growth rate, 100 seed $\mathrm{wt}=100$ seed weight, Pod no. $=$ number of pods $\mathrm{m}^{-2}$.

Our results showed positive association of sink capacity (rate of partitioning) with yield under drought as well as DRI. Further, this association was found to intensify with increased severity of drought during the post-flowering stage. The existence of ample genetic variation and control on filled pod number, viz., sink capacity, was showed in chickpea (Srinivasan and Gaur, 2011), and therefore it is possible to produce chickpeas with a high sink capacity through breeding program.

Chickpea genotype ICC 7571, a landrace collected from Israel in 1974 , seems to be unique in its consistency in drought tolerance across years. Under drought stress in 2005-2006, it produced the highest drought yield $\left(118.0 \mathrm{~g} \mathrm{~m}^{-2}\right)$ among the entries. This genotype showed the highest CGR among the entries $\left(3.13 \mathrm{~g} \mathrm{~m}^{-2} \mathrm{day}^{-1}\right)$, and fairly low WUE till early reproductive stage indicated by the second highest $\Delta^{13} \mathrm{C}$ as $20.4 \%$. In a previous report, ICC 7571 had been shown to possess a larger root biomass ranking the top 16th among the chickpea mini-core germplasm collection which comprise 216 diverse chickpea genotypes (Kashiwagi et al., 2005). It points out that a larger root system of ICC7571 might have helped to acquire necessary soil water for superior crop growth. ICC 7571 could be used as an ideal breeding material to improve the drought yield in chickpea.

Although selection for DRI in chickpea is important and this DRI is relatively less prone to $G \times E$, it is still necessary to select additionally for the most suitable phenology to match the available soil water and the extent of winter of the target location (so as to have minimum evaporative loss of stored water) and for the yield potential for the best yield stability. Accessions ICC 4958, ICC 14595 and ICC 1230 as shown in Fig. 4B and C yielded beyond that is explained by the DRI as these were early duration and best suited for Patancheru conditions. This has also been shown as a need in earlier studies (Johansen et al., 1994; Krishnamurthy et al., 1999).

\section{Conclusion}

For achieving the best drought response index (DRI) and consequently improved yields under drought through active water use strategy, it is crucial to seek greater crop growth rate and lower water use efficiency and thereby ensure enhancing soil water acquisition. Low water use efficiency till flowering stage was found to be another trait that is indicative of greater yields under terminal drought environments. The $\Delta^{13} \mathrm{C}$ measurement at post-flowering stage could help in screening large number of chickpea genotypes with lower water use efficiency. Ensuring relatively large sink (pods) quantity could also contribute to improved yield under drought environments. Under severe drought, the sink activity (rate of partitioning) would play a major role in improving drought yield in chickpea.

\section{Acknowledgment}

This research was partly supported by the unrestricted funds from the Japanese Government earmarked for chickpea drought tolerance research and breeding in ICRISAT.

\section{References}

Ashok, I.S., Hussain, A., Prasad, T.G., Udaya Kumar, M., Nageswara Rao, R.C., Wright, G.C., 1999. Variation in transpiration efficiency and carbon isotope discrimination in cowpea. Aust. J. Plant Physiol. 26, 503-510.
Bartlett, M.S., 1937. Properties of sufficiency and statistical tests. Proc. R. Soc. Lond. A Math. Phys. Sci., 268-282.

Bidinger, F.R., Mahalakshmi, V., Rao, G.D.P., 1987a. Assessment of drought resistance in pearl millet [Pennisetum americanum (L.) Leeke]. I. Factors affecting yield under stress. Aust. J. Agr. Res. 38, 37-48.

Bidinger, F.R., Mahalakshmi, V., Rao, G.D.P., 1987b. Assessment of drought resistance in pearl millet [Pennisetum americanum (L.) Leeke]. II. Estimation of genotype response to stress. Aust. J. Agr. Res. 38, 49-59.

Blum, A., 2005. Drought resistance, water-use efficiency, and yield potential-are they aompatible, dissonant, or mutually exclusive? Aust. J. Agr. Res. 56 1159-1168.

Brockwell, J., 1982. Inoculation methods for field experimenters and farmers. In: Vincent, J.M. (Ed.), Nitrogen Fixation in Legumes. Academic Press, New York, pp 211-221.

Food and Agricultural Organization of the United Nations. FAOSTAT. Available at http://faostat3.fao.org/home/index.html; 2012.

Condon, A.G., Richards, R.A., Rebetzke, G.J., Farquhar, G.D., 2002. Improving intrinsic water-use efficiency and crop yield. Crop Sci. 42, 122-131.

Farquhar, G.D., O"Leary, M.H., Berry, J.A., 1982. On the relationship between carbon isotope discrimination and the intercellular carbon dioxide concentration in leaves. Aust. J. Plant Physiol. 9, 121-137.

Farquhar, G.D., Ehleringer, J.R., Hubick, K.T., 1989. Carbon isotope discrimination and photosynthesis. Annu. Rev. Plant Physiol. Plant Mol. Biol. 40, 503-537.

Gowda, C.L.L., Parthasarathy Rao, P., Tripathy, S., Gaur, P.M., Deshmukh, R.B., 2009 Regional shift in chickpea production in India. In: Ali, M., KumarF S. (Eds.), Milestones in Food Legumes Research. Indian Institute of Pulses Research, Kanpur pp. 21-35.

Johansen, C., Krishnamurthy, L., Saxena, N.P., Sethi, S.C., 1994. Genotypic variation in moisture response of chickpea grown under line-source sprinklers in a semi-arid tropical environment. Field Crops Res. 37, 103-112.

Kato, Y., Kamoshita, A., Yamagishi, J., 2008. Preflowering abortion reduces spikelet number in upland rice (Oryza sativa L.) under water stress. Crop Sci. 48 , 2389-2395.

Kashiwagi, J., Krishnamurthy, L., Upadhyaya, H.D., Krishna, H., Chandra, S., Vadez, V., Serraj, R., 2005. Genetic variability of drought-avoidance root traits in the mini-core germplasm collection of chickpea (Cicer arietinum L.). Euphytica 146, 213-222.

Kashiwagi, J., Krishnamurthy, L., Crouch, J.H., Serraj, R., 2006a. Variability of root length density and its contributions to seed yield in chickpea (Cicer arietinum L.) under terminal drought stress. Field Crops Res. 95, 171-181.

Kashiwagi, J., Krishnamurthy, L., Singh, S., Guar, P.M., Upadhyaya, H.D., Panwar, J.D.S., Basu, P.S., Ito, O., Tobita, S., 2006b. Relationships between transpiration efficiency and carbon isotope discrimination in chickpea (C. arietinum L.). Int. Chickpea Pigeonpea News. Lett. 13, 19-21.

Kashiwagi, J., Krishnamurthy, L., Gaur, P.M., Chandra, S., Upadhyaya, H.D., 2008a Estimation of gene effects of the drought avoidance root characteristics in chickpea (C. arietinum L.). Field Crops Res. 105, 64-69.

Kashiwagi, J., Krishnamurthy, L., Upadhyaya, H.D., Gaur, P.M., 2008b. Rapid screening technique for canopy temperature status and its relevance to drought tolerance improvement in chickpea. J. SAT Agric. Res. 6, 1-4.

Krishnamurthy, L., Johansen, C., Sethi, S.C., 1999. Investigation of factors determining genotypic differences in seed yield of non-irrigated and irrigated chickpeas using a physiological model of yield determination. J. Agronomy Crop Sci. 183 9-17.

Krishnamurthy, L., Serraj, R., Kashiwagi, J., Panwar, J.D.S., Koteswara Rao, Y., Kumar J., 2004. Multilocation analysis of yield and yield components of a chickpea (Cicer arietinum L.) mapping population grown under terminal drought. Ind. J. Pulses Res. 17, 17-24.

Krishnamurthy, L., Kashiwagi, J., Gaur, P.M., Upadhyaya, H.D., Vadez, V., 2010 Sources of tolerance to terminal drought in the chickpea (Cicer arietinum L.) minicore germplasm. Field Crops Res. 119, 322-330.

Kumar, J., Haware, M.P., Smithon, J.B., 1985. Registration of four short-duration, Fusarium wilt-resistant kabuli (Garbanzo) chickpea germplasm. Crop Sci. 25 576-577.

Kumar, J., Rao, B.V., 2001. Registration of ICCV96029, super early and double podded chickpea germplasm. Crop Sci. 41, 605-606.

Kumar, J., Abbo, S., 2001. Genetics of flowering time in chickpea and its bearing on productivity in semiarid environments. In: Spaks, D.L. (Ed.), Advances in Agronomy, vol. 2. Academic press, New York, p. 122

Ludlow, M.M., Muchow, R.C., 1990. Critical evaluation of traits for improving crop yields in water-limited environments. In: Brady, N.C. (Ed.), Advances in Agronomy, vol. 43. Academic press, New York, pp. 107-153.

Merah, O., 2001. Potential importance of water status traits for durum wheat improvement under Mediterranean conditions. J. Agric. Sci. 137, 139-145 
Oya, T., Nepomuceno, A.L., Neumaier, N., Farias, J.R.B., Tobita, S., Ito, O., 2004. Drought tolerance characteristics of Brazilian Soybean Cultivars-evaluation and characterization of drought tolerance of various Brazilian soybean cultivars in the field. Plant Prod. Sci 7, 129-137.

Purushothaman, R., Zaman-Allah, M., Mallikarjuna, N., Pannirselvam, R., Krishnamurthy, L., Gowda, C.L.L., 2013. Root anatomical traits and their possible contribution to drought tolerance in grain legumes. Plant Prod. Sci. 16, 1-8.

Saxena, N.P., 1987. Screening for adaptation to drought: case studies with chickpea and pigeonpea. In: Saxena, N.P., Johansen, C. (Eds.), Adaptation of Chickpea and Pigeonpea to Abiotic Stresses. Proceedings of Consultant's Workshop. International Crops Research Institute for the Semi-Arid Tropics, Patancheru, India, pp. 63-76.

Saxena, N.P., 2003. Management of drought in chickpea: holistic approach. In: Saxena, N.P. (Ed.), Management of Agricultural Drought: Agronomic and Genetic options. Oxford \& IBH publishing, New Delhi, pp. 103-122.
Sinclair, T.R.,Zwieniecki, M.A., Holbrook, N.M., 2008. Low leaf hydraulic conductance associated with drought tolerance in soybean. Physiol. Plant. 132, 446-451.

Srinivasan, S., Gaur, P.M., 2011. Genetics and characterization of an open flower mutant in chickpea. J. Hered., 1-6.

Udayakumar, M., Sheshshayee, M.S., Nataraj, K.N., Bindu Madhava, H., Devendra, R., Aftab Hussain, I.S., Prasad, T.G., 1998. Why has breeding for water use efficiency not been successful? An analysis and alternate approach to exploit this trait for crop improvement. Curr. Sci. 74, 994-1000.

Varshney, R.K., Pazhamala, L., Kashiwagi, J., Gaur, P.M., Krishnamurthy, L., Hoising ton, D.A., 2011. Genomics and physiological approaches for root trait breeding to improve drought tolerance in chickpea (Cicer arietinum L.). In: Antonio Costa de Oliveira, Varshney, R.K. (Eds.), Root Genomics. Springer, Germany, pp. 233-250.

Zaman-Allah1, M., Jenkinson, D.M., Vadez, V., 2011. A conservative pattern of water use, rather than deep or profuse rooting, is critical for the terminal drought tolerance of chickpea. J. Exp. Bot. 62, 4239-4252. 